Review Article

Open Access

\title{
Salmonella Kentucky: prevalence and challenges in Nigeria and the Africa continent
}

\author{
Igomu, E. E. \\ Bacterial Vaccine Production Division, National Veterinary Research Institute, P. M. B. 01 Vom, Nigeria \\ Correspondence to: elayonigomu@gmail.com; +2348032786224
}

\begin{abstract}
:
Salmonella Kentucky is ubiquitous in most African countries and the multidrug resistant (MDR) strains remain underreported across the continent. In Nigeria, poverty, inter country livestock trades, nomadic system of cattle production, indiscriminate use of antibiotics and prevalent immuno-compromising diseases such as human immunodeficiency virus/acquired immune deficiency syndrome (HIV/AIDS) and tuberculosis are factors that have enabled ease of transmission and complications of $S$. Kentucky infections. In the present decade, $S$. Kentucky is reported to be the most prevalent serovar associated with poultry in Nigeria, but very few reports underline the risk associated with consumption of poultry and acquisition of MDR S. Kentucky strains. The Nigerian poultry is one of the most commercialized subsectors of Nigerian agriculture, therefore, the presence of $S$. Kentucky especially strains carrying broad spectrum antimicrobial resistance pose a great risk to public health. The lack of proper monitoring, surveillance, isolation and control of the multidrug resistant $S$. Kentucky will remain a challenge to the export potential of the Nigerian poultry subsector and livestock in general. As a nation, modalities and actions against the smuggling of poultry products, indiscriminate use of antibiotics and nomadic system for the production of dairy and beef that promotes spread of virulent strains of Salmonellae must change. The impact of non-typhoidal salmonellosis in humans in Nigeria also remains under studied and under reported, especially those caused by $S$. Kentucky ST198. Compounding these concerns is the lack of commercial veterinary or human vaccines against $S$. Kentucky or where vaccines against the broad serogroup C non-typhoidal Salmonella (NTS) are available, they are rarely supplied, with no evidence they could be cross-protective. This review emphasizes the emergence and widespread occurrence of MDR S. Kentucky strains on the African continent, and discussed risk factors contributing to its spread in Nigeria and the potential public health challenge especially to high-risk immunocompromised individuals.
\end{abstract}

Keywords: Salmonella Kentucky, ST198 strain, multidrug resistant, tuberculosis, HIV/AIDS, Nigeria, Africa

Received April 30, 2020; Revised May 8, 2020; Accepted May 10, 2020

Copyright 2020 AJCEM Open Access. This article is licensed and distributed under the terms of the Creative Commons Attrition 4.0 International License $<$ a rel="license" href="http://creativecommons.org/licenses/by/4.0/", which permits unrestricted use, distribution and reproduction in any medium, provided credit is given to the original author(s) and the source.

\section{Salmonella Kentucky: prévalence et défis au Nigeria et sur le continent africain}

\author{
Igomu, E. E. \\ Division de la production de vaccins bactériens, Institut national de recherche vétérinaire, \\ P. M. B. 01 Vom, Nigéria \\ Correspondance à: elayonigomu@gmail.com; +2348032786224
}

\begin{abstract}
Abstrait:
Salmonella Kentucky est omniprésente dans la plupart des pays africains et les souches multirésistantes (MDR) restent sous-déclarées à travers le continent. Au Nigéria, la pauvreté, les échanges de bétail entre pays, le système d'élevage nomade, l'utilisation aveugle d'antibiotiques et les maladies immunodéprimantes prévalentes telles que le virus de l'immunodéficience humaine/le syndrome d'immunodéficience acquise (VIH/SIDA) et la
\end{abstract}


tuberculose sont des facteurs qui ont facilité la transmission et complications des infections à $S$. Kentucky. Au cours de la présente décennie, $S$. Kentucky serait le sérotype le plus répandu associé à la volaille au Nigéria, mais très peu de rapports soulignent le risque associé à la consommation de volaille et à l'acquisition de souches MDR S. Kentucky. La volaille nigériane est l'un des sous-secteurs les plus commercialisés de l'agriculture nigériane, par conséquent, la présence de $S$. Kentucky, en particulier les souches présentant une résistance antimicrobienne à large spectre, pose un grand risque pour la santé publique. L'absence de suivi, de surveillance, d'isolement et de contrôle adéquats du $S$. Kentucky multirésistant résistera toujours au défi du potentiel d'exportation du soussecteur de la volaille nigérian et du bétail en général. En tant que nation, les modalités et les actions contre la contrebande de produits de volaille, l'utilisation aveugle d'antibiotiques et le système nomade pour la production de produits laitiers et de boeuf qui favorisent la propagation de souches virulentes de salmonelles doivent changer. L'impact de la salmonellose non typhoïde chez l'homme au Nigeria reste également sous-étudié et sous-signalé, en particulier ceux causés par S. Kentucky ST198. À ces inquiétudes s'ajoute le manque de vaccins commerciaux vétérinaires ou humains contre $S$. Kentucky ou là où des vaccins contre les Salmonella non typhoïde du sérogroupe C sont disponibles, ils sont rarement fournis, sans aucune preuve qu'ils pourraient être de protection croisée. Cette revue met l'accent sur l'émergence et la présence généralisée de souches MDR $S$. Kentucky sur le continent africain, et a discuté des facteurs de risque contribuant à sa propagation au Nigéria et du défi potentiel de santé publique en particulier pour les personnes immunodéprimées à haut risque.

Mots-clés: Salmonella Kentucky, souche ST198, multirésistante, tuberculose, VIH/SIDA, Nigéria, Afrique

\section{Introduction:}

Salmonella is a Gram negative, nonlactose fermenting and non-sporing facultative anaerobic rod-shaped bacteria belonging to the family Enterobacteriaceae (1). There are over 2,600 different serovars and more than 50 serogroups in the genus Salmonella as described in the Kauffman White scheme, and majority of the recognized serovars cause infections in human and animals worldwide $(2,3)$. Salmonella can be subdivided into two broad groups with respect to pathogenesis of the bacteria. The first group of serovars is host specific and typically produces systemic disease but in the absence of disease, these strains poorly colonize the intestine of their host and are rarely involved in human food-poisoning (4). Serovars in this group include Salmonella Gallinarum and Pullorum in poultry, Salmonella Dublin in cattle, and Salmonella Typhi and Salmonella Paratyphi A, B and C in man (5). In human, Salmonella Typhi and Salmonella Paratyphi A are collectively referred to as typhoidal salmonellosis (also called enteric fevers) causing fatal disease of human called typhoid fever and paratyphoid fever respectively (5). The second group of serovars is known as the non-typhoidal Salmonella (NTS). These serovars typically produces food poisoning in man and only cause systemic disease under certain conditions, such as during parturition, in infants and young children, elderly, and immunocompromised persons (6). In animals, they are usually asymptomatic, but systemic diseases have been reported in birds in-lay, very young or old animals, or after some viral infections, and in experimental animals challenged with high bacterial colony forming units $(4,7)$.
In 2010, the global incidence of human NTS gastroenteritis was estimated to be 93 million cases, of which 80.3 million were via food-borne transmission, with over 155,000 deaths reported $(8,9)$. In the same year, a separate report on NTS gastroenteritis put the estimate at approximately 3.4 million invasive infections with 681,000 deaths; $57 \%$ of these illnesses and deaths were reported to have occurred in Africa (10). These NTS strains can infect and colonize a broad range of vertebrate animals and most of these lineages are adapted to humans or may be adapted or restricted to particular non-human animal species $(5,11)$.

There are diversities in the epidemiology and host range for NTS serovars and their propensity to cause bloodstream infection and severe human disease varies $(6,12)$. Invasive NTS is associated with several forms of immunocompromised states unlike in typhoidal salmonellosis, for which there are no clear clinical associations with classic immunocompromising conditions (13). These immunocompromising states include; disorders of oxidative cellular killing such as chronic granulomatous disease, in which NTS is described as the commonest cause of bloodstream infection and the third leading cause of infections (14), in children who are homozygous for sickle cell disease (15), and in people with HIV-AIDS, which is worsened in Africa where this disease is driven in part by co-infection with malaria (10).

This review attempts to provide an update information on the epidemiology of $S$. Kentucky in Africa and Nigeria with associated risk factors that may promote the acquisition and propagation of antimicrobial resistant determinants within the serovar in Nigeria and 
the impact such widespread strains may have on public health and the Nigerian livestock subsector.

\section{Methodology:}

An online search of relevant published materials and bibliographic citations including review articles, original articles, books and conference papers through the period 1990 to 2019 was done on Google, Google scholar, PubMed and African Journals Online (AJOL). The keywords utilized for the search were 'salmonellosis', 'Salmonella Kentucky ST198', 'multidrug resistant $S$. Kentucky', 'prevalent Salmonella serovar in Nigeria', 'nontyphoidal salmonellosis in Nigeria', 'epidemiology of nontyphoidal salmonellosis in Africa', 'antimicrobial Salmonella pathogen', 'nontyphoidal salmonellosis and HIV infection in Nigeria', 'salmonellosis and tuberculosis infection in Nigeria', 'and Salmonella Kentucky in the Nigerian cattle and poultry subsector'. Reference materials totaling 186 were identified, and following screening of all the materials, 79 reference materials were selected for the review.

\section{Characteristic features of $\boldsymbol{S}$. Kentucky:}

Salmonella enterica subsp. enterica serovar Kentucky (antigenic formula 8, 20: i: z6) is a serovar of the 0: 8 (C2-C3) serogroup $(16,17)$. Salmonella serogroup $C$ consists of highly diverse serovars among which 37 are reported to account for the majority of human Salmonella infection as compared to 17 and 11 serovars for serogroups $B$ and $D$, respectively (6). Currently, four out of the ten most lethal serovars of Salmonella in the United States are from serogroup $\mathrm{C}$ and strains within this serogroup are multidrug resistant (9). Salmonella Kentucky on several occasions has been isolated from healthy poultry, dairy cows and occasionally from people with clinical disease $(16,17)$. S. Kentucky was less often identified in human salmonellosis averaging 62 cases per annum in the United States between 1996 to 2004, but rose to 123 cases in 2006; accordingly, the prevalence in chickens rose from $25 \%$ in 1997 to approximately $50 \%$ in 2007 (18-20).

While the virulence and colonization mechanism of $S$. Enteritidis (serogroup D), and S. Typhimurium (serogroup B) have been extensively studied, studies on $S$. Kentucky are few (21). If left unattended to, S. Kentucky exhibits the potential to emerge as the most prevalent NTS serovar in human disease as it has acquired virulent chromosomal and plasmid factors that gives it superior colonization capabilities of its host and environment (2224). Johnson et al., (22) reported that $S$. Kentucky harbors a ColV virulence plasmid gene which significantly increased its ability to colonize chicken caecum and cause extraintestinal disease through competitive exclusion. Turki et al., (23) identified the presence of virulence invA/spvC genes and quorum sensing sdiA gene and elucidated the ability of $S$. Kentucky to form biofilms, which is a microbially derived sessile community characterized by cells that are irreversibly attached to a substratum or interface or to each other, and are embedded in a matrix of extracellular polymeric substances (EPS) that they have produced, and which exhibit altered phenotype with respect to growth rate and gene transcription $(25,26)$.

Interestingly, it has been observed that the resistance of biofilm cells to antimicrobials is significantly increased compared with what is normally seen with the same cells being planktonic $(27,28)$. Thus, it is believed that biofilm formation enhances the capacity of pathogenic Salmonella bacteria to survive stresses that are commonly encountered both within food processing, as well as during host infection (29). These virulence factors confer on $S$. Kentucky a superior capacity to persist longer in the environment and explains its ability to acquire virulence plasmid genes from avian pathogenic Escherichia coli (APEC) and other non-generic bacteria through horizontal gene transfer $(22,23)$.

Salmonella Kentucky ST198 is an emerging risk for foodborne illness across the globe (30). Whole genome sequencing of isolates obtained from five continents (Africa, Europe, Middle East, Asia and North America) showed that multidrug-resistant (MDR) S. Kentucky isolates belonged to a single lineage, which was estimated to emerged circa 1989 following the acquisition of the AMR-associated Salmonella genomic island (SGI) 1 (variant SGI1-K), which confers resistance to ampicillin, streptomycin, gentamicin, sulfamethoxazole and tetracycline (31). The MDR clone has undergone substitution mutations in the quinolone-resistance-determining regions (QRDRs) of DNA gyase (gyrA) and topoisomerase IV (parC) genes, such that most strains carry three QRDR mutations which together confer resistance to ciprofloxacin. Remarkably, each genome of the MDR clone carried a different SGI1-K derivative structure; this variation could be attributed to IS26n mediated insertions and deletions (31). The genome sequence of $S$. enterica serotype Kentucky ST198 isolate 201001922 has been 
deposited in GenBank under the accession number CP028357 (31).

\section{Epidemiology of $S$. Kentucky infection in African countries}

In time past, the most widely reported serovars associated with invasive non-typhoidal salmonellosis across Africa were $S$. Typhimurium (serogroup B) and $S$. Enteritidis (serogroup D) $(14,32)$. But recent studies are now showing a significant shift in the predominant Salmonella serovar associated with poultry and human infections $(18,24,33)$. Salmonella Kentucky is reported to be the most widely spread serovar on the African continent where virulent strains of this bacteria is reported to have originated, and this is now of global public health concern $(6,24)$.

A multiple-antibiotic resistant strain of S. Kentucky with multilocus sequence type (MLST) 198 was reported to have originated from Egypt. Isolates of this strain of $S$. Kentucky manifested high degree of broad range antibiotic resistance especially toward ciprofloxacin which is considered the mainstay drug of choice for Salmonella treatment $(24,34)$. Subsequently this clone has been identified in a number of other African countries (24). This strain was originally considered to be travel related but has now been identified in poultry, various food materials and environments. This emerging strain has acquired chromosomal and plasmid factors over time that give it a superior colonization capacity in host animals (22). In Tunisia, 57 strains of $S$. Kentucky were isolated from different sources between 2005 and 2008 and were characterized by their antimicrobial and mercury resistance profiles and other virulent factors (23). A total of $10.6 \%$ of these isolates demonstrated multidrug-resistance against 3 to 13 antibiotics with ciprofloxacin resistance occurring in 33\% of the human isolates (23).

Salmonella is considered in Morocco as the major cause of food poisoning in the country, although Salmonella cases remains underreported. Salmonella Kentucky resistant to ciprofloxacin was first identified in an eightmonth old child who was admitted at the paediatric department of University Hospital Centre Ibn-Rochd in Casablanca, Morocco, with an acute febrile diarrheal illness $(35,36)$. In a study of the prevalence of drug susceptibility and molecular characteristics of NTS isolated from laying hens in three Moroccan regions; Rabat-Salé-Zemmour-Zaër, Souss-Massa-Drâa and the grand Casablanca, seven Salmonella enterica serovars were identified; $S$. Enteritidis
$(37.5 \%)$, S. Kentucky $(31.2 \%)$, S. Infantis (10. $.9 \%)$, S. Typhimurium $(6.2 \%)$, S. Thompson $(6.2 \%)$, S. Agona $(4.6 \%)$, and S. Amsterdam (3.1\%). Amongst these serovars, S. Kentucky showed the highest level of resistance (25\%) to the different drugs tested (37).

In a separate study undertaken by Allaoui et al., (38) in 2017 on the prevalence, sensitivity to antibiotics and distribution of Salmonella spp. serotypes in broiler turkey in the north-west of Morocco, twenty farms were inspected three times for the purpose of the study. S. Kentucky was the most prevalent serovar $(33.8 \%)$ isolated, followed by $S$. Parkroyal (16.3\%) and S. Agona (11.3\%), and the results of the Salmonellae antimicrobial resistance showed that multi-drug resistant strains (resistant to three or more antibiotics) accounted for $80.6 \%$ of the strains isolated; $4.8 \%$ were resistant to ceftazidime, ceftriaxone and cefotaxime (38) with S. Kentucky and S. Agona showing the highest resistance rates to the tested drugs. The risk factors associated with contamination were linked to; the cleanout period, antibiotic treatment, infection of turkey poults at placement, manure storage, keeping sick turkeys in the turkey house, season and age of turkeys at the time of sampling (38). The findings of a widespread antibiotic resistant strains and high prevalence of $S$. Kentucky reported by Allaoui et al., (38), was in accordance with other studies undertaken in other parts of Morocco $(37,39-42)$. These studies established the threat posed by laying hens and turkey to the effective control of human NTS foodborne diseases in Morocco.

In Uganda, Afema et al., (43) reported a high prevalence of $S$. Kentucky in poultry and significantly high isolation rates in humans. Livestock (poultry, ruminant and swine), environmental and human samples were taken from 14 sites in Kampala, the largest city of Uganda. Thirty-two serovars of Salmonella were isolated from these sources amongst which were S. Enteritidis, S. Kentucky, $S$. Newport and $S$. Typhimurium. Interestingly, $S$. Enteritidis was not detected in human wastewater samples and $S$. Typhimurium was poorly isolated from this sample (43). Sensitivity and resistance profile to 15 antimicrobials (amikacin, amoxicillin-clavulanic acid, ampicillin, cefotaxime, cefoxitin, ceftiofur, chloramphenicol, ciprofloxacin, gentamicin, kanamycin, nalidixic acid, streptomycin, sulfisoxazole, tetracycline, and trimethoprim-sulfamethoxazole) showed that $S$. Kentucky exhibited extensive multi-drug resistance pattern and had diverse resistance profile from human, environmental and poultry sources (43), for 
instance, the SSUTCipNa resistance profile was shared by $S$. Kentucky from human, environmental and poultry sources. A deca-resistant profile, ACKSSuSxTAmcCipNa was unique to poultry, and $S$. Kentucky isolated from poultry were multi-drug resistant, while other serovars found in poultry were pan-susceptible or had low resistance profile (43). Also, shared genotypes and antimicrobial resistance phenotypes were found in NTS from human, livestock and environmental sources, suggesting the occurrence of zoonotic and environmental transmissions (43).

In West Africa, reports from Ghana indicated that the prevalence and antimicrobial resistance pattern for Salmonellae was higher in $S$. Kentucky. In two regions of Ghana, fecal, dust, feed and drinking water samples were collected from 75 commercial egg-laying and broiler farms while skin neck samples were collected from broilers representing different flocks at a local slaughterhouse. Of the 200 samples collected, Salmonella was detected in 94 of them representing $47 \%$ with an overall flock prevalence of $44.0 \%$. Sixteen serovars of Salmonella were identified with $S$. Kentucky the most prevalent $(18.1 \%)$ followed by $S$. Nima $(12.8 \%)$, S. Muenster $(10.6 \%)$, S. Enteritidis (10.6\%) and S. Virchow (9.6\%). All the strains of $S$. Kentucky were reported to show multidrug resistance (two or more antimicrobials) including ciprofloxacin, nalidixic acid and tetracycline (44).

In Senegal, recent reports on the prevalence and presence of $S$. Kentucky are sparse but earlier findings showed fluctuations in their isolation rates. A total of 1623 clinical isolates of Salmonella belonging to 229 serotypes were received by the Senegalese Reference Center for Enterobacteria from January 1999 to December 2009 (45). The most common serotypes isolated were $S$. Enteritidis $(19 \%)$, S. Typhi $(8 \%)$, S. Typhimurium $(7 \%)$ and $S$. Kentucky (4\%). There were noticeable significant increases in the prevalence of resistance to amoxicillin $(0.9 \%$ in 1999 to $11.1 \%$ in 2009) and nalidixic acid $(0.9 \%$ in 1999 to $26.7 \%$ in 2009$)$ in NTS serotypes (45). The constant threats that arise from sudden increase in emergence and prevalence of new serovars of Salmonellae are often due to unknown or unclear reasons (46).

\section{Epidemiology of $S$. Kentucky infection in Nigeria and the concern}

Nigeria is reported to have widespread presence of $S$. Kentucky serovar, and the multidrug resistant strain ST198 that is now of global concern has been isolated $(24,33,47)$. Useh et al., in 2016 (48) reported the findings of a study undertaken in southwest and north central Nigeria where epidemiological samples were collected, with $S$. Kentucky the most common serotype isolated from poultry in these regions, followed by $S$. Zega and $S$. Hertston, which have previously been isolated from diarrheal cases among children in Niger State. Salmonella Enteritidis, which was thought to be the most common serotype associated with poultry worldwide, was absent in the study.

Another extensive and elaborate study cutting across all the six geopolitical zones in Nigeria was undertaken (49) with representative samples of five different types (litter, dust, faeces, feed and water) collected from commercial chicken layer farms in selected States in these regions. In this survey, $S$. Kentucky was the most widely spread serovar with prevalence of $16.2 \%$ and highest isolation from faeces (23\%) and feeds $(22.7 \%)$, followed by $S$. Poona (5.6\%) and $S$. Elisabethville. Also, $S$. Kentucky was distributed across the country, whereas the other less frequent serovars had a more circumscribed diffusion (49). The usual high presence in faeces also indicated high environmental contamination that allowed the pathogen to persist within the poultry flock.

In a separate study involving three southwestern States (Lagos, Ogun and Oyo), Mshelbwala et al., in 2017 (50) reported that S. Kentucky was the second most prevalent serovar with prevalence rate of $24.3 \%$. The study reported further that although this serovar was less often associated with mortality in birds, the finding seems to contradict this norm (50) as sampled and challenged birds showed classical lesions consistent with that exhibited by the host specific serotypes. The findings of Fagbamila et al., (49) and Mshelbwala et al., (50) are amongst the most recent reports regarding $S$. Kentucky in the Nigerian poultry subsector. The risk factors reported in these studies that allowed for widespread presence of this serovar included poor biosecurity, poor sanitation measures, and lack of adequate monitoring and surveillance in the farms.

Earlier reports by Raufu et al., $(47,51)$ identified the presence of the highly pathogenic S. Kentucky ST198 strain that encode genes resistant to multiple antimicrobials. In the study, S. Kentucky isolates from chicken and farm environmental sources (litter, faeces, water) in Ibadan (southwestern) and Maiduguri (northeastern) Nigeria were screened to estab- 
lish for the presence of ciprofloxacin resistant genes ( $S$. Kentucky CIPR strain) using pulse field gel electrophoresis (PFGE) and minimum inhibitory concentration (MIC) in 2007, 2010 and 2011. Six percent of the samples were positive for $S$. Kentucky and all resistant to nalidixic acid and ciprofloxacin (47). The isolates showed genotypic relatedness to $S$. Kentucky CIPR strain based on XbaI PFGE fingerprinting, indicating the presence of widespread $S$. Kentucky CIPR clone within poultry and farm environment in these regions (47).

Nigeria is the most populous and one of the largest countries on the African continent, with a total geographical area of 923,768 square kilometers (52). The estimated population of the country in 2013 was 174.5 million people with a population growth rate of $3 \%$ per annum and the National Population Commission (NPC) put the estimate at over 193 million in $2016(53,54)$. The Nigerian economic statistics reveal an economic growth rate that averaged over $7 \%$ per annum in recent decades, making Nigeria one of the fastest growing economies on the continent (55). Nonetheless, this growth has neither reduced poverty nor created a stable environment for jobs thus; unemployment is still very high, and more than $60 \%$ of the population lives below the poverty line (56).

Poultry and cattle production play significant roles in the epidemiology of Salmonellae in Nigeria, because they act as reservoirs, and excrete the organism in their faeces, and their products are easily contaminated by infected animals $(49,57,58)$. The Nigerian poultry industry has expanded rapidly in recent years despite encountering several shortcomings like the global financial crisis, inadequate credit facilities, a weak level of biosecurity and a relatively low level of production (59). The Nigerian poultry industry rose from approximately 150,700 million chickens in 2005 to 192,313 million in 2010 (60), thus it is one of the most commercialized and growing subsectors of Nigerian agriculture $(53,61)$; and also accounts for about $25 \%$ of the country local meat production.

The advantages of poultry production over other livestock production can be explained by the fact that poultry birds are good converters of feed into useable protein in meat and eggs, production costs per unit remain relatively low, and return on investment is high. Therefore, subsistence farmers need a relatively small amount of capital to start a poultry farm. Also, poultry meat is tender and acceptable to consumers, regardless of their religious backgrounds.
Furthermore, the production cycle is quite short, so capital is not tied up for too long, and eggs, which is a major products of poultry farming, are more affordable for the common people than other sources of animal protein $(62,63)$. This makes the poultry subsector an essential part of the Nigerian economy and a good source of high-quality protein for the teeming population.

In food-producing animals, especially poultry, infection with Salmonella has a direct impact on the global marketing of the respective livestock animals and livestockderived food products (64). The high rate of production of poultry in Nigeria signifies a high rate consumption of its products; however, this also means a concomitant increase in the cases of Salmonella-associated gastroenteritis (65) and thus makes S. Kentucky ST198 an imminent threat to the poultry subsector and a limiting factor to its export potential. Thus, prevention of Salmonella infections is important for the profitable expansion of the poultry industry. Despite this assertion, an effective prevention and control measure cannot be undertaken unless the status of the disease and epidemiology are well elucidated (62). There are very few African countries that report surveillance data on Salmonella and as such, very limited information is available on Salmonella isolation for the Africa continent $(58,66)$.

One of the factors that may contribute to the proliferation of bacteria strains resistant to multiple antimicrobials in Nigeria would be the indiscriminate use of antimicrobials in the poultry subsector. Indiscriminate use of antimicrobials in any environment creates selection pressures that favours the survival of antibiotic-resistant strains (67) and in Nigeria, the practice of routinely giving antimicrobials to domestic livestock for growth promotion and prophylaxis is an important factor in the emergence of antibiotic-resistant bacteria in the food chain $(65,68)$. The occurrence of ciprofloxacin resistant serovar is of economic importance since fluoroquinolone resistance has implications for both veterinary and human therapy ciprofloxacin is a mainstay drug in the treatment of salmonellosis thus; the abuse of these medications in poultry could result in the emergence of resistant zoonotic bacteria (62).

\section{Risk factors for $S$. Kentucky infection}

\section{Nomadic system of cattle rearing}

Food animals such as cattle play significant roles in the epidemiology of Salmonella, because they act as reservoirs and 
excrete Salmonellae in their faeces (57), therefore, meat and meat products that are contaminated during slaughter and processing, pose severe health risks, and infections can also result from cattle contact $(69,70)$. Beef from cattle is considered an important source of salmonellae in Nigeria as they are widely consumed, and reports have shown that they are source for transmission of zoonotic Salmonella serovar including $S$. Kentucky to man. The potential for zoonotic transmission is further increased given limited capacity for sanitation, nomadic system of cattle production and co-mingling of this livestock with human population (71).

In 2017, Fashae et al., (71) compared phenotypic and genotypic characteristics of Salmonellae isolated from cattle and humans in a study of faecal samples from diarrhoeic patients, healthy population, cattle beef at slaughter, farms, and markets. The Salmonella isolates were serotyped and their antimicrobial susceptibility pattern determined (71) while whole genome sequencing (WGS) of selected isolates and bioinformatics analysis were used to identify the multilocus sequence type (MLST), plasmid replicons, antimicrobial resistance genes, and genetic relatedness by single nucleotide polymorphism (SNP).

The MLST sequence types (ST) include ST 584, ST 198, ST 562 and ST 512 for $S$. Colindale, $S$. Kentucky $S$. Rubislaw and $S$. Urbana respectively. The findings in this study showed multiple antibiotic resistant serovar exhibited by $S$. Kentucky and $S$. Typhimurium. In the cattle market, both $S$. Kentucky and $S$. Ealing co-predominated (40\% each) (71). There was an overlapping of Salmonella serovars between humans and cattle and also between the diarrhoeic patients and healthy women, and such serovars included $S$. Colindale, S. Give, S. Corvallis, S. Oranienburg and $S$. Kentucky. Majority (83.3\%) of the resistant isolates obtained from the healthy women comprised six serovars including $S$. Kentucky, while all the three resistant isolates from cattle were $S$. Kentucky (71), and all the ciprofloxacin resistant isolates belonged to $S$. Kentucky. Furthermore, majority (57.1\%) of the multidrug resistant (resistance to $\geq 3$ antimicrobials) isolates were $S$. Kentucky (71). The findings of this study buttressed the fact that in Nigeria, cattle are important reservoir of diverse serovars of Salmonellae including the highly virulent multiple antimicrobial resistant S. Kentucky strains.

\section{Inter country livestock trade}

Trading of livestock between African countries is an important means for the transmission of zoonotic pathogens between nations. Despite the huge potentials of the Nigerian poultry subsector, the 330 billion Naira chicken meat segment of the industry, is still struggling to grow because of the smuggling of large volumes of imported chicken products into her markets (72). The poultry industry estimates that about 1.2 million metric tons of poultry products are smuggled into Nigeria annually, primarily from Brazil and Asia, and although the government of Nigeria has placed a ban on the importation of poultry products, implementation has not been effective (72).

The Western and Central African countries are reported to import large quantities of frozen poultry products from the European Union (EU). Between 1996 and 2003, chicken imports from the EU to ECOWAS countries increased from 125,000 to 860,000 metric tons. Benin was the major importer, followed by Ghana, Nigeria, Senegal, Togo, and Côte d'Ivoire. Yet about 90 percent of Benin's poultry imports are informally reexported to Nigeria as reported by the World Bank. The illegal importation of these poultry products, porosity and poor manning of the Nigeria border and inadequate surveillance policy on Salmonella spp. play important role in the acquisition and transmission of the $S$. Kentucky serovar to the country.

\section{Indiscriminate use of antimicrobials}

The use antimicrobials cannot be overlooked by their proven importance for a sustainable livestock production especially in the control and treatment of livestock infections and their use as growth promoters (73). The use of antimicrobials in any environment creates selection pressures that favors the survival of antibiotic-resistant strains (67), and in Nigeria, the practice of routinely administering antimicrobials in the livestock industry as growth promoters and prophylaxis is an important factor that promotes the emergence of antibiotic-resistant bacteria in the food chain with concomitant socioeconomic and public health risk $(65,68,73)$. Furthermore, the abusive use of antimicrobials in many parts of the world is recognized as key drivers for the emergence and spread of antimicrobial resistance (74-77).

In a study conducted by multi-stage sampling technique of 454 farmers in 11 communities within 11 Local Government Areas (LGAs) of Kaduna and Oyo States in northern and southern Nigeria respectively to ascertain antimicrobials usage and practices by livestock 
farmers in these regions of the country (73). Antimicrobial usages were collected through interviews, questionnaire and focus group discussions. The study revealed that antimicrobials were widely distributed, easily accessible and commonly used in livestock production, and antimicrobials that are crucial in human therapy including flouroquinolones were widely used in animals as prophylactics. Also, potentially harmful antimicrobials including furazolidones and chloramphenicol which have been banned for use in humans and animals were freely marketed and used in livestock production (73). Most of the respondents in the study acknowledged that it was standard practice for drugs and antimicrobials to be prescribed and administered to animals, but on the farm, they buy and administer antimicrobials without professional consultation (73).

In another study, Ogunleye et al., (78) in 2010 reported the widespread occurrence of multidrug resistant Salmonella serovars from poultry disease outbreaks in two southwestern Nigerian states (Oyo and Ogun) where a total of $73.3 \%$ of Salmonella isolates tested were multi-drug resistant (resistance to four or eight antibiotics) which included resistance to ciprofloxacin, nalidixic acid, chloramphenicol, streptomycin, kanamycin, ampicillin, neomycin, and tetracycline, and specifically, 63.4\% were ciprofloxacin resistant (78). The practice of avoiding veterinary personnel and laboratory investigations in the diagnosis of disease prior to institution of antimicrobial therapy could lead to improper usage that promotes the development of antimicrobial resistance in bacterial strains (73).

\section{Use of antimicrobial residue in animal feed}

The indiscriminate use of therapeutic and prophylactic antimicrobials administered in feedstuffs in the Nigerian livestock industry is a managerial practice that gives opportunity for antimicrobials to enter the human food chain (through eggs, milk, meat, etc.) especially when drug withdrawal periods are not adhered to (79). Medicated feedstuffs are primarily a mixture of animal feed and veterinary medicinal products, which are usually authorized for the animal species for which the feed is intended and contains high antimicrobial concentrations depending on its aim, physiological status and state of health of the animal.

The use of these feedstuffs accompanied by the tendencies for human error in compounding and contamination of the antibiotic negative feed with antimicrobials, improper production, poor handling and storage practices, little proportions of medicated feedstuff being left in production line or storage tanks leading to the cross-contamination of next batches of antimicrobial negative feed, pose severe risks and safety concerns to both animals and man (79), and promote the spread of antibiotic resistant pathogens such as S. Kentucky ST198.

\section{Potential challenges of S. Kentucky NTS to HIV/AIDS patients}

Data from the United Nations Programme on human immunodeficiency virus and the acquired immune deficiency syndrome (UNAIDS) put the estimate number of people in Nigeria living with HIV in 2018 at 1.9 million (80) which makes the nation the second largest HIV epidemic in the world and approximately 160,000 people died from AIDS related illnesses in Nigeria in 2017 (81). Although new survey indicates that Nigeria has HIV prevalence among adults (aged 15 - 49 years) at $1.5 \%$, this was previously estimated at $2.8 \%$ (82), and the recent drops in prevalence estimates for Nigeria were attributed to better surveillance (83). Six States in Nigeria that account for $41 \%$ of people living with HIV are Kaduna, Akwa Ibom, Benue, Lagos, Oyo, and Kano (84) but the prevalence of HIV is highest in Nigeria southern states (known as the south-south zone) at $5.5 \%$ and lowest in the southeast zone with a prevalence of $1.8 \%$. Previous reports showed that there are higher rates of HIV in rural areas (4\%) than in urban ones $(3 \%)(85)$.

Reports have indicated that the use of antimicrobials for growth-promotion, prophylaxis, and treatment of food animals increases the prevalence of resistance in human pathogens, particularly NTS in people living with HIV/AIDS. Researches to ascertain the prevalence of NTS amongst people living with HIV/AIDS has been undertaken in the country. In Ekiti State, a study was undertaken to evaluate the relationship between consumption of poultry products and prevalence of HIV /AIDS, with collection of 100 stool and 50 blood samples from a total of 150 HIV/AIDS patients attending Federal Medical Centre, IdoEkiti, and 50 faecal samples from broiler chickens for culture and identification of NTS as well as their antimicrobial susceptibilities and similarities (86). Eighteen NTS isolates were identified from the human with a prevalence of $12 \%$ while four NTS isolates were identified from poultry broiler-chicken with prevalence of $8 \%$. Isolates from broiler chickens had a higher average resistance to 
seven commonly prescribed antibiotics including ciprofloxacin (78.6\%) when compared to the human isolate (53.9\%). Furthermore, most of the isolates from human and broiler chicken showed resistance to more than one antibiotic expressing the concern that antimicrobial resistance is wide spread in both poultry and persons living with HIV/AIDS (86).

\section{Potential challenges of S. Kentucky NTS to tuberculosis patients}

The lack of epidemiological data on the impact of NTS on tuberculosis (TB) or records implicating opportunistic infections caused by antimicrobial resistant Salmonellae on TB patients is rare. In 1995, a 33 years old woman with recurrent Salmonella Enteritis infection was found to have underlying hepatic tuberculosis (87). Ciprofloxacin, ceftriaxone, penicillin and chloramphenicol were among the antimicrobials administered that failed to eradicate the recurrent nontyphoidal salmonellosis. Over the past decades, S. Kentucky has been identified as most prevalent multidrug resistant Salmonella serovar in human salmonellosis infection $(22,24)$.

The World Health organization prioritizes fluoroquinolone resistant Salmonellae amongst the high-risk pathogens to human health (31) and because mycobacterium, causative agent for TB, are fairly susceptible to quinolones, repeated ciprofloxacin therapy which is the main stay drug for treatment of Salmonellosis can mask early and proper diagnosis of TB (87). Since antimicrobial resistance, HIV and poverty are the backbone for the spread of tuberculosis globally (88), and with these conditions endemic in Africa and Nigeria, it becomes pertinent for the Nigerian government and health organizations to draft up policies as they design national TB control programme that will prevent possible complications caused by this pathogen.

It should be noted that Nigeria is ranked among the 30 high TB burden countries of the world and one of the top three of ten countries that accounted for $80 \%$ of the total gap between TB incidence and reported cases in $2017(89,90)$. Studies from settings outside Nigeria reveal poor governance practices as responsible for the increased scourge in the country. The lack of specific TB legislation, inconsistencies in the enforcement of policies on isolation of TB patients in health facilities $(91,92)$, Low government funding $(93,94)$, inadequate trained personnel and lack of public awareness (95), poor integration into the general health system, weak programme impl- ementation, sub-optimal quality of care in the private sector, and insufficient advocacy around TB (88) limited the strategic vision and responsiveness of TB control programmes. Multidrug resistant (MDR) TB cases have made this menace terrifying for patients. Taking cognizance of the high incidence and epidemiologic significance of occurrence of MDR-TB strains, it is imperative that determination of MDR-TB burden and complications that may be due to $S$. Kentucky ST198 in acquisition of MDR-TB strains in patients be elucidated to inform proper case management and overall planning of TB control activities.

\section{Conclusion:}

The World health organization prioritizes fluoroquinolone resistant Salmonellae amongst the high-risk pathogens to human health and S. Kentucky ST198 wears this cap. The genomic/genetic efficiency of this strain has put it in the frontline as an emerging threat to public health and the commercial livestock subsector. The lack of epidemiological data, proper monitoring and surveillance systems, and indiscriminate use of antimicrobials in Nigeria and the African continent has enabled the widespread propagation of this serovar. On a continent where poverty and immuno-compromising diseases such as HIV/ AIDS and tuberculosis are endemic, S. Kentucky ST198 has shown explicit potential as an ideal opportunistic non-typhoidal Salmonella serovar that could compound these conditions.

The private sectors, government agencies and international organizations on the African continent are key players that can be involved in forestalling the propagation of this strain in the environment. Strategic policies can be made and informed decisions taken to curtail the spread of $S$. Kentucky ST198, for example, there should be regulations and restrictions on the use and over-the-counter sale of veterinary antimicrobials, provision of biosecurity facilities and trained personnel at inter country livestock markets and meat slaughtering/processing plants, adequate surveillance, monitoring and data recording practices are measures that can limit its spread.

\section{References:}

1. Cheesbrough, M. District laboratory practice in tropical countries E.C.B.S. Cambridge University press. 2000; 2: 256-267.

2. Scallan, E., Hoekstra, R. M., Angulo, F. J., Tauxe, R. V., Widdowson, M. A., and Roy, S. L. Food borne illness acquired in the United States-major pathogens. Emerg Infect Dis. 2011; 17 (1): 7-15. 
3. Issenhuth-Jeanjean, S., Roggentin, P., Mikoleit, M., Guibourdenches, M., Pinna, E, Nair, S., Fields, P. I., and Weill, F. X. Supplement 2008-2010 (no. 48 ) to the White-Kauffmann-Le Minor scheme. Res Microbiol. 2014; 165: 526-530.

4. Barrow P. A. Salmonella infections: immune and non-immune protection with vaccines. Avian Pathol. 2007; 36: 1-13.

5. Sanderson, K. E., Liu, S..., and Johnston, R. N. Salmonella Typhi and Salmonella Paratyphi A. Mol Med Microbiol. 2015; 2 (71): 1275 - 1306.

6. Parry, C. M., Thomas, S., Aspinall, E. J., Cooke, R. P., Rogerson, S. J., Harries, A. D. and Beeching, N. J. A retrospective study of secondary bacteremia in hospitalized adults with community acquired non typhoidal Salmonella gastroenteritis. BMC Infect Dis. 2013; 13: 107 - 110.

7. Revolledo, L. Avian Salmonellosis, vaccines and immune mechanisms of protection: present and future perspectives. Poult Hith Biosecur. 2012; 24: 5- 9.

8. Majowicz, S. E., Musto, J., and Scallan, E. The global burden of nontyphoidal Salmonella gastroenteritis. Clin Infect Dis. 2010; 50: 882889.

9. Fuche, F. J., Sow, O., Simon, R. and Tennant, S. M. Salmonella Serogroup C: Current Status of Vaccines and Why They Are Needed. Clin Vacc and Immunol. 2016; 23 (9): 737-745.

10. Ao, T. T., Feasey, N. A., Gordon, M. A., Keddy, K. H., Angulo, F. J., and Crump, J. A. Global burden of invasive nontyphoidal Salmonella disease. Emerg Infect Dis. 2015; 21 : 941 - 945.

11. Feasey, N. A., Archer, B. N., Heyderman, R. S. Sooka, A., Dennis, B., and Gordon, M. A. Typhoid fever and invasive non typhoidal salmonellosis, Malawi and South Africa. Emerg Infect Dis. 2010; 16: 1448 - 1451

12. Jones, T. F., Ingram, L. A., Cieslak, P. R., et al., Salmonellosis outcomes differ substantially by serotype. J Infect Dis. 2008; 198: 109-114.

13. Gordon, M. A., Graham, S. M., Walsh, A. L., et al., Epidemics of invasive Salmonella enterica serovar Enteritidis and $S$. enterica serovar Typhimurium infection associated with multidrug resistance among adults and children in Malawi. Clin Infect Dis. 2008; 46: 963 - 969.

14. Crump, J. A., Sjolund-Karlsson, M., Gordon, M. A., and Parrye, M. C. Epidemiology, Clinical presentation, laboratory diagnosis, antimicrobial resistance and antimicrobial management of invasive Salmonella infections. Clin Microbiol Rev. 2015; 28 (4): 901 - 936.

15. Sommet, J., Missud, F., Holvoet. L., Ithier, G., Lorrot, M., Benkerrou, M., and Faye, A. Morbidity among child travellers with sickle cell disease visiting tropical areas: an observational study in a French tertiary care center. Arch Dis Children. 2013; 98: 533 - 536.

16. Haley, B. J., Kim, S. W., Pettengill, J., Luo, Y. Karns, J. S., and Van Kessel, J. A. S. Genomic and Evolutionary Analysis of Two Salmonella enterica Serovar Kentucky Sequence Types Isolated from Bovine and Poultry Sources in North America. PLoS One. 2016; 11 (10): e0161225. doi:10.1371.

17. Switt, M. I. A. Salmonella Kentucky. In: Weller, L. D. (ed). Salmonella enterica serovar Kentucky strain SRC73. Food Safety. 2017:1 - 3.

18. Center for Disease Control and Prevention (CDC) Salmonella surveillance: Annual summary, 2006. U.S. Department of Health and Human Services, CDC, Atlanta, GA. 2008

19. Fricke, W. F., McDermott, P. F., Mammel, M. K., Zhao, S., and Johnson, T. J. Antimicrobial resistance-conferring plasmids with similarity to virulence plasmids from avian pathogenic Escherichia coli strains in Salmonella enterica serovar Kentucky isolates from poultry. Appl Environ Microbiol. 2009; 75: 5963-5971.

20. Food and Drug Administration. (FDA). National Antimicrobial Resistance Monitoring System enteric bacteria (NARMS): 2007 executive report. U.S. Department of Health and Human Services, FDA, Rockville, MD. 2010

21. Foley, L. S., Rajesh N., Irene, B. H., Timothy J. J. Jing $H_{\text {., }}$ and Steven C. R. Population Dynamics of Salmonella enterica Serotypes in Commercial Egg and Poultry Production. Appl Environ Microbiol. 2011; 77: 4273-4279.

22. Johnson, T. J., Thorsness, J. L., Anderson, C. P. Lynne, A. M., and Foley, S. L. Horizontal Gene Transfer of a ColV Plasmid Has Resulted in a Dominant Avian Clonal Type of Salmonella enterica Serovar Kentucky. PLoS One 2010; 5 (12): 1 - 10 .

23. Turki, Y., Ouzari, H., Mehri, I., Ben Aissa, R., and Hassen, A. Biofilm formation, virulence gene and multidrug resistance in Salmonella Kentucky isolated in Tunisia. Food Res Int. 2012; 45: 940 946.

24. Le Hello, S., Bekhit A., Granier, S. A., et al., The global establishment of a highly flouroquinolone resistant Salmonella enterica serotype Kentucky ST198 strain. Front Microbiol. 2013; 4: 395 - 399.

25. Lazazzera, B.A., Lessons from DNA microarray analysis: the gene expression profile of biofilms. Curr Opin Microbiol. 2005; 8: 222-227

26. Shemesh, M., Tam, A., and Steinberg, D. Differential gene expression profiling of Streptococcus mutants cultured under biofilm and planktonic conditions. Microbiol. 2007; 153: 13071317

27. Mah, T. F. C., and O'Toole, G. A. Mechanisms of biofilm resistance to antimicrobial agents. Trends Microbiol. 2001; pp. 34-39

28. Gilbert, P., Allison, D. G., and McBain, A. J. Biofilms in vitro and in vivo: Do singular mechanisms imply cross-resistance. J Appl Microbiol. 2002; 92:98 - 110.

29. Efstathios, G., Nikos, C., Panagiotis, S., and George, J. N. Attachment and Biofilm Formation by Salmonella in food processing Environments. Salmonella a Dangerous Foodborne Pathogen 2012; 8:157 - 180 .

30. Salehi, S., Howe, K., Lawrence, M. L., Brooks, J. P., Bailey, R. H., and Karsi, A. Salmonella enterica serovar Kentucky flagella are required for broiler skin adhesion and Caco-2 cell invasion. Appl Environ Microbiol. 2017; 83: 2115 - 2116. https://doi.org/10.1128/AEM.02115-16.

31. Hawkey, J., Le Hello, S., Doublet, B., et al., Global phylogenomics of multidrug-resistant Salmonella enterica serotype Kentucky ST198. Microbial genomics 2019; 5: 1-12. doi:10.1099/mgen.0.000269

32. Gordon, M. A., Kankwatira, A. M. K., and Mwafulirwa, G. Invasive nontyphoidal Salmonella establish systemic intracellular infection in HIV infected adults: an emerging disease pathogenesis. Clin Infect Dis. 2010; 50: 953-962.

33. Le Hello, S., Hendriksen, R. S., Doublet, B., et al., International Spread of an Epidemic; Population of Salmonella enterica serotype Kentucky ST198 Resistant to Ciprofloxacin. J Infect Dis. 2011; 204: 675- 684

34. Nourhan N. M., Sadek, M. A. and Wafaa, R. A Studies on pathogenicity of Salmonella enterica serovar Kentucky in chicken. Egypt J Com Pathol Clin Pathol. 2014; 27 (1): 18-25.

35. Bouchrif, B., Karraouan, B., Ennaji, M. M. and Timinouni, M. Quinolones-resistant Salmonella 
spp. in Casablanca - Morocco. Casablanca Maroc Med Mal Infect. 2008; 38: 615-616.

36. Rouahi, N., Zouhdi, M., Benabderrazek, F., et al., Analyse des données des trios dernières années sur les salmonelloses au maroc (1995-1997). Biologie Infect Tome. 1998; 5: 3 - 10

37. Ziyate, N., Karraouan, B., Kadiri, A., Darkaoui, S. Soulaymani, A., and Bouchrif, B. Prevalence and antimicrobial resistance of Salmonella isolates in Moroccan laying hens farms was undertaken. J Appl Poult Res. 2016; 25 (4): 539-546.

38. Allaoui, A. E., Rhazi Filali, F., Ameur, N., and Bouchrif, B. Contamination of broiler turkey farms by Salmonella spp. in Morocco: prevalence, antimicrobial resistance and associated risk factors. Sci Tech Rev. 2017; 36 (3): 1 - 30

39. Cohen, N., Ennaji, H., Bouchrif, B., Hassar, M. and Karib, H. Comparative study of microbiologica quality of raw poultry meat at various seasons and for different slaughtering processes in Casablanca (Morocco). J Appl Poult Res. 2007; 16 (4): 502 508.

40. Ammari, S., Laglaoui, A., En-nanei, L., Bertrand S., Wildemauwe, C., Barrijal, S., and Abid, M. Characterization of Salmonella Enteritidis isolated from foods and patients in Northern Morocco. J Infect Dev Ctries. 2009; 3: 695 - 703.

41. Bouchrif, B., Paglietti, B., Murgia, M., Piana, A., Cohen, N., Ennaji, M. M., Rubino, S., and Timinouni, M. Prevalence and Antibiotic-resistance of Salmonella isolated from food in Morocco. J Infect Dev Ctries. 2009; 3 (1): 35 - 40

42. Karraouan, B., Ziyate, N., Ed-Dra, A., Amajoud, N., Boutaib, R., Akil, A., and Bouchrif, B. Salmonella Kentucky: Antimicrobial resistance and molecular analysis of clinical animal and environment isolates Morocco. J Infect Dev Ctries. 2017; 11 (4): 368-370.

43. Afema, J., A., Byarugaba, D. K., Shah, D., H., Atukwase, E., Nambi, M., and Sischo, W., M. Potential Sources and Transmission of Salmonella and Antimicrobial Resistance in Kampala, Uganda. PLoS One. 2016; 11 (3): 1 - 21.

44. Andoh, L. A., Dalsgaard, A., Obiri-Danso, K., Newman, M. J., Barco, L., and Olsen J. E. Prevalence and antimicrobial resistance of Salmonella serovars isolated from poultry in Ghana. Epid Infect. 2016; 144 (15): 3288-3299.

45. Harrois, D., Breurec, S., Seck, A., et al. Prevalence and characterization of extendedspectrum b-lactamase-producing clinical Salmonella enterica isolates in Dakar, Senegal, from 1999 to 2009. Clin Microbiol Infect. 2013; 20: 109-116.

46. Van Immerseel, F. Immunity conferred by live Salmonella vaccine strains in chickens and their mode of action. Salmonella $360^{\circ}$ Bulletin, Review. 2016: 1-3

47. Raufu, I. A., Fashae, K., Ameh, J. A., Ambali, A. Ogunsola, F. T., Coker, A. O., and Hendriksen, R. $\mathrm{S}$. Persistence of fluoroquinolone-resistant Salmonella enterica serovar Kentucky from poultry and poultry sources in Nigeria. J Infect Dev Ctries. 2014; 8 (3): 384-388.

48. Useh, N. M., Ngbede, E. O., Akange, N., et al. Draft Genome Sequences of 37 Salmonella enterica Strains Isolated from Poultry Sources in Nigeria. Genome Announcement. 2016; 4 (3): 315- 316

49. Fagbamila, I. O., Barco, L., Mancin, M., et al. Salmonella serovars and their distribution in Nigerian commercial chicken layer farms. PLoS One. 2017; 12 (3): 1-15.

50. Mshelbwala, F. M., Ibrahim, N. D., Saidu, S. N., et al., Motile Salmonella serotypes causing high mortality in poultry farms in the three South-
Western States of Nigeria. Vet Rec Open. 2017; 4: e000247. doi:10.1136/vetreco-2017-000247.

51. Raufu, I., Bortolaia, V., Svendsen, C. A., Ameh, J. A., Ambali, A. G., Aarestrup, F. M., and Hendriksen, R. S. The first attempt of an active integrated laboratory-based Salmonella surveillance programme in the north-eastern region of Nigeria. J Appl Microbiol. 2013; 115, 10591067.

52. Manyong, V. M., Ikpi, A., Olayemi, J. K., Yusuf, S. A., Omonona, B. T., Okoruwa, V., and Idachaba F. S. Agriculture in Nigeria: Identifying opportunities for increased commercialization and investment. IITA, Ibadan, Nigeria. 2005; 22: 190

53. United State Department of Agriculture (USDA) USDA International Egg and Poultry: Nigeria. The Poultry site. 2013

54. National Bureau of Statistics. Demographic Statistics Bulletin, May 2018: 12-13.

55. Byerlee, D., Andres, G. F., Giertz, A., and Palmade, V. Growing Africa: Unlocking the potential of Agribusiness. AFTFP/AFTAI. The World Bank. http://documents. worldbank.org. 2013.

56. African Economic Outlook. Nigeria 2012 http://www.africaneconomicoutlook.org. 2012

57. Rodriguez-Rivera, L. D., Wright, E. M., Siler, J. D. Elton, M., Cummings, K. J., Warnick, L. D., and Wiedmann, M. Subtype analysis of Salmonella solated from sub-clinically infected dairy cattle and dairy farm environments reveals the presence of both human- and bovine- associated subtypes. Vet Microbiol. 2014; 170 (3-4): 307-316.

58. Muhammad, M., Muhammad, L. U., Ambali, A. G. Mani, A. U., Azard, S., and Barco, L. Prevalence of Salmonella associated with chick mortality at hatching and their susceptibility to antimicrobial agents. Vet Microbiol. 2010; 140: 131-135.

59. Food and Agricultural Organization (FAO) Assessment of the Nigerian poultry market chain to improve biosecurity. 2008 http://www.fao.org/3/a-ak778e.pdf

60. Food and Agricultural Organization (FAO). Data Source 2015: FAOSTAT | FAO Statistics Division 2015; December 2015

61. Adene, D. F., and Oguntade, A. E. The structure and importance of the commercial and villagebased poultry industry in Nigeria. FAO Consultancy Report.

http://www.fao.org/docs/eims/upload//214281/po ultrysector. 2006.

62. Agbaje, M., Davies, R., Oyekunle, M. A., Ojo, O. E., Fasina, F. O., and Akinduti, P. A. Observation on the occurrence and transmission pattern of Salmonella Gallinarum in commercial poultry farms in Ogun State, South Western Nigeria. Afr ] Microbiol Res. 2010; 4 (9): 796-800.

63. Aboki, E., Jongur, A. A. U., and Onu, J. I. Productivity and Technical Efficiency of Family Poultry Production in Kurmi Local Government Area of Taraba State, Nigeria. J Agric Sustainab. 2013; 4 (1): $52-66$

64. Magwedere, K., Rauff, D., De Klerk, G., Keddy, K. $\mathrm{H}$. , and Dziva, $\mathrm{F}$. Incidence of nontyphoidal Salmonella in food producing animals, animal feed, and associated environment in South Africa, 2012-2014. Clin Infect Dis. 2015; 61: 283-289.

65. Fasure, A. K., Deji-Agboola, A. M., and Akinyemi, K. O. Antimicrobial resistance patterns and emerging fluoroquinolone resistant Salmonella isolates from poultry and asymptomatic poultry workers. Afr J Microbiol Res. 2012; 6: 2610-2615.

66. Barbiour, E. K., Ayyash, D. B., Alturkistni, W., et al., Impact of sporadic reporting of poultry Salmonella serovars from selected developing countries. J Infect Dev Ctries. 2015; 9: 1-7. 
67. Adeleke, M. A., Akatah, H. A., Hassan, A. O., and Adebimpe, W. O. Microbial Load and Multiple Drug Resistance of Pathogenic Bacteria Isolated from Faeces and Body Surfaces of Cockroaches in an Urban Area of Southwestern Nigeria. J Microbiol Biotech Food Sci. 2012; 1: 1448-1461.

68. Shah, A. H., and Korejo, N. A. Antimicrobial Resistance Profile of Salmonella Serovars Isolated from Chicken Meat. J Vet Animal Sci. 2012; 2: 40 $-46$.

69. Cummings, K. J., Warnick, L. D., Davis, M. A., Eckmann, K., Gröhn, Y. T., Hoelzer, K., and Besser, T. E. Farm animal contact as risk factor for transmission of bovine-associated Salmonella subtypes. Emerg Infect Dis. 2012; 18 (12): 19291936.

70. Leekitcharoenphon, P., Raufu, I., Nielsen, M. T., et al., Investigating Salmonella Eko from various sources in Nigeria by whole genome sequencing to identify the source of human infections. PLoS One. 2016; 11 (5): e0156212. https://doi.org/10.1371/journal.pone.0156212

71. Fashae, K., Leekitcharoenphon, P., and Hendriksen, R. S. Phenotypic and Genotypic Comparison of Salmonellae from Diarrhoeic and Healthy Humans and Cattle, Nigeria. Wiley Zoonos Pub HIth. 2017; 65: 185-195.

72. Okojie, J. Nigerian Poultry Farmers say imports threaten 330 billion Naira Market. Businessday Nigeria.Bissinessday.ng/exclusives/article/Nigerian Poultry Farmers say imports threaten 330 billion Naira Market, 2017.

73. Ojo, O. E., Fabusoro, E., Majasan, A. A., and Dipeolu, M. A. Antimicrobials in animal production: usage and practices among livestock farmers in Oyo and Kaduna States of Nigeria. Trop Animal Hlth Prod. 2016; 48 (1):189-197.

74. Aminov, R. I., and Mackie, R. I. Evolution and ecology of antibiotic resistance genes. FEMS Microbiol Lett. 2007; 271: 147-61.

75. APUA. AMROAR Scientific Meeting Report on Commensals as Reservoirs of Antibiotic Resistance. In: ROAR (ed.). Boston: APUA 2008.

76. Aarestrup, F. M., Wegener, H. C., and Collignon, P. Resistance of Bacteria of the Food Chain: Epidemiology and Control Strategies. Expert Rev Anti Infect Ther. 2008; 6: 733-750.

77. Acar, J. F., and Moulin, G. Antimicrobial resistance at farm level. Rev Sci Tech. 2006; 25: 775-792.

78. Ogunleye, A. O., Ajuwape, A. T. P., and Adetosoye, A. I. Fluoroquinolone resistant Salmonella enterica of poultry origin from southwestern states of Nigeria'. Bulletin Animal HIth Prod Afr. 2010; 58 (3): 216-221.

79. Federal Ministries of Agriculture, Environment and Health (FMAEH). Antimicrobial Residue in Animal feed; Situation Analysis and Recommendations. 2017

80. UNAIDS Data. Nigeria - country data. 2019: 128129
81. The Joint United Nations Programme on HIV and AIDS (UNAIDS) Report. 2010. http://data.unaids.org/pub/report/2010/nigeria_2 010 country progress report en.pdf. 2017

82. Nigeria AIDS Indicator and Impact Survey (NAIIS) HIV/AIDS in Nigeria- pushing for the last mile. Press release, March 14, 2018

83. PEPFAR 'Large National Survey Shows Smaller HIV Epidemic in Nigeria Than Once Thought and Highlights Key Gaps Toward Reaching HIV Epidemic Control'. PEPFAR release; US Department of State, March 14, 2019

84. National Agency for the control of AIDS (NACA) 'National Strategic Framework on HIV and AIDS: $2017-2021$ ', 2017

85. National Agency for the control of AIDS (NACA), 2015. 'Nigeria GARPR 2015'[pdf]

86. Oluyege, A., O., and Ojo-Bola, O. Prevalence of Non-Typhoidal Salmonella among HIV/AIDS Patients and Poultry Chicken in Ekiti State. $\mathrm{Br}$ Microbiol Res J. 2015; 6 (2): 113-118.

87. Trauner, M., Grasmug, E., Stauber, R. E., et al., Recurrent Salmonella Enteritidis sepsis and hepatic tuberculosis. Gut. 1995; 37: 136 - 139.

88. Ogbuabor, D. C., and Onwujekwe, O. E. Governance of tuberculosis control programme in Nigeria. Infect Dis Poverty 2019; 8 (45): 1-11. https://doi.org/10.1186/s40249-019-0556-2

89. World Health Organization (WHO). Global Tuberculosis report, 2018. Geneva: World Health Organization; 2018.

90. World Health Organization (WHO). Global Tuberculosis report. Country Profiles for 30 High TB Burden Countries. 2019; $214-215$

91. Slagle, T., Youssef, M. B., Calonge, G., and Amor, Y.B. Lessons from Africa: developing a global human rights framework for tuberculosis control and prevention. BMC Int Health Hum Rights. $2014 ; 14(1): 34$.

92. Verani, A. R., Emerson, C. N, Lederer, P., et al., The role of the law in reducing tuberculosis transmission in Botswana, South Africa and Zambia. Bull World HIth Organ. 2016; 94(6):415.

93. Khan, W. M., Smith, H., Qadeer, E., and Hassounah, S. Knowledge and perceptions of national and provincial tuberculosis control programme managers in Pakistan about the WHO STOP tuberculosis strategy: a qualitative study. JRSM Open. 2016; 8(1):2054270416675084.

94. Pai, M., Daftary, A., and Satyanarayana, S. Tuberculosis control: challenges and opportunities for India. Trans Roy Soc Trop Med Hyg. 2016; 110 (3): 158-160.

95. Rahman, N. H. A., and Mokhtar, K. S. Challenges of national Tuberculosis control program implementation: the Malaysian experience. P-Soc Behav Sci. 2015; 172: 578-584. 